\title{
New Cutting Method of Skew Bevel Gear Based on the Tooth Generating Line
}

\author{
Peng Gu, a ${ }^{1}$ Xinping $\mathrm{Yu}^{2, \mathrm{~b}}$ Xia Liu ${ }^{3, \mathrm{c}}$ \\ Liqin Miao ${ }^{4, \mathrm{~d}}$ Chuang $\mathrm{Li}^{5, \mathrm{e}}$ and Keqin Chen ${ }^{6, f}$ \\ Changchun equipment and technology research institute \\ (Changchun 130012,China)
}

\section{Keywords: Bevel gear; Generating line; Spherical involute; Milling method}

\begin{abstract}
The generating principle of skew bevel gear tooth face is analyzed about spherical involute, base cone and base plane that tangent to the base cone is constructed. Firstly, based on the relevant motion between the base cone and the generating line in the generating process of tooth surface, a new machining method of skew bevel gear using disc milling tool is explored. Secondly, motion equation of finish machining is set up by cutting process analysis. Finally, structure of machine and cutter is designed and the performance of this method is verified by experimental results. The result indicates that: the milling process of the skew bevel gear with no theoretic error can be realized by 3-axis linkage based on the proposed theory that has a simple motion and easy to be controlled.
\end{abstract}

\section{Introduction}

Bevel gear as transfer intersect axis motion and power drive device is widely used for power machinery in the field of vehicles, aerospace, petroleum, metallurgy, etc. Skew bevel gear as a kind of gear has many advantages such as high strength, good gear tooth coincident coefficient, smooth operation, high bearing capacity, and so on[1-2]. Early skew bevel gear tooth surface mainly formed by planning processing method, but due to the machining efficiency and precision was low, it was replaced by circular bevel gear that made by face milling cutting of Gleason gear system[3].

According to the principle of tooth profile meshing, bevel gear is spherical involute tooth profile. Currently Gleason cutting tooth method adopts the way that back cone expand on the plane of imaginary equivalent cylindrical gear approximate substitution, conical surface formed by straight cutting edge rotary that constitute cutting plane of gear cutting cutter head to envelope generative conjugate convex and concave tooth flank. Due to the project is used for approximate method, so an error in the principle of design and processing is generated on cutting bevel gear system, resulting in two gear can not mesh correctly and contact poor. In order to obtain a better meshing performance, , need to be modified repeatedly, at the same time, must be machined in pairs and assembled in pairs, and shall be repeated adjustments to the cutting machine tool. Now the manufacturing process of spiral bevel gear is very complicated, the quality control is very difficult, the machine tools and cutters are very expensive [4-6].

Due to the spherical involute linear skew bevel gears have many advantages, such as instantaneous speed transmission ratio is constant, the gear can be interchangeable, using for precision transmission, etc. According to the proposed principle, this paper to explore the method of generating shape line cutting principle, this paper explores the method of machining the helical bevel gear tooth flank with no principle error, circular cutter is used as cutting tool, the line made by the vertical intersection of the blade end face and the base plane is the tooth surface generating line, and the bevel gear tooth surface milling can be realized by three axis linkage[7-9].

\section{The Formation of Spherical Involute Skew Bevel Gear Tooth Surface}

Inner spherical there is a vertex through the center and bottom, that tangent to the base cone gear and intersects at the base cone, then formed a imaginary circle plan $\mathrm{Q}$, as shown in Fig. 1. When the $\mathrm{Q}$ round plane and the base cone relative rolling, $\mathrm{M}$ point on the circumference of $\mathrm{Q}$ round flat 
formed a trajectory on the spherical, this trajectory is defined as spherical involute. Q round plane gear is defined as base circle plane or base plane of base cone gear.

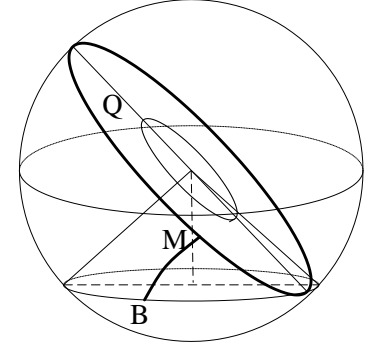

Figure 1. Spherical involute tooth face forming diagram

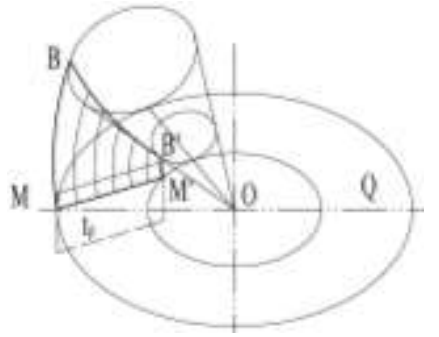

Figure 2. The generating process of cone involute surface

As shown in Fig. 2, the Q plane and the base cone in the process of relative motion as described above, Spherical involute $\mathrm{MB}$ is obtained by generating motion of point $\mathrm{M}$ on the big end of bevel gear, the point $\mathbf{M}$ is on the $\mathrm{Q}$ circle plane, in the same way, spherical involute $\mathbf{M}^{\prime} \mathbf{B}^{\prime}$ is obtained by generating motion of point $\mathbf{M}^{\prime}$ on the small end of bevel gear, the space involute surface is formed by the infinite point on curve $\mathbf{M M}^{\prime}$ formed the involute cluster, this involute surface is conical involute gear tooth surface, $\mathbf{M M}^{\prime}$ is called tooth surface generating line. When generating linear is straight line that is not through the circle center $\mathrm{O}$, the generating tooth surface is spherical involute spiral bevel gear tooth surface, through straight line $\mathbf{M} \mathbf{M}^{\prime}$ to do a plane $\mathbf{t}_{\mathbf{p}}$ that is vertical to Q plane, obviously plane $\mathbf{t}_{\mathbf{p}}$ tangent to tooth surface on straight line $\mathbf{M} \mathbf{M}^{\prime}$, so plane $\mathbf{t}_{\mathbf{p}}$ is called generating line of tooth surface or tangent plane.

\section{The Principle of Skew Bevel Gear Tooth}

In Fig. 3, the base circle plane Q having generating motion in the base cone surface, the rotating motion between $Q$ plane rotating around its central axis with angular velocity vector $\varpi^{(\mathbf{q})}$ and center rotating around base cone axis with angular velocity vector $-\varpi^{(\mathbf{t})}$ have been composed, the motion of circular cone relative to the base cone is $\varpi^{(\mathbf{q})}-\varpi^{(\mathbf{t})}$ in the center point. When the base cone rotating around its central axis with angular velocity vector $\varpi^{(\mathbf{t})}$, the generating motion of tooth surface can be divided into: base cone relative to the space fixed coordinate system rotating around its central axis with angular velocity vector $\varpi^{(t)}, Q$ and generating liner relative to the space fixed coordinate system rotating around its central axis with angular velocity vector $\varpi^{(\mathbf{q})}$, the relationship between each other is:

$$
\frac{\omega_{\mathbf{q}}}{\omega_{\mathbf{t}}}=\sin \delta_{\mathbf{b}}
$$

The shadow part is the region between the root cone and face cone ,that is bevel gear in cutting region of $Q$ plane, according to the above motion relation, the milling cutter strings $\mathbf{W}_{\mathbf{d}} \mathbf{V}_{\mathbf{d}}$ rotating 
around Q with angular velocity $\varpi^{(\mathbf{q})}$ in Q plane, when generating line in the $\mathbf{W V}$, small bevel gear side is cut by milling cutter strings. The generating shape liner is located on the left side of the root when moving to the position $\mathbf{W}^{\prime}$, that means cutter cut into tooth root, that become over-cutting. The cutting edge rotating with angular velocity $\varpi_{\mathbf{q}}$ follow $Q$ while slipping along the string direction have their own slip, the synthetic motion $\mathbf{W}$ points along the direction $\mathbf{O} \mathbf{W}_{\mathbf{n}}$, to ensure the point $\mathrm{W}$ is always in the root that does not occur over-cutting, as shown in Fig. 5. Due to the cutter head rotating around $\mathrm{O}$ with angular velocity $\varpi^{(\mathbf{q})}$ on Q plane, so it is possible to get W point perpendicular to the direction of straight line $\mathbf{O W}$ that the speed is $\mathbf{R}_{0} \mathbf{s e c} \varpi_{\mathbf{q}}\left(\mathbf{t}+\mathbf{t}_{0}\right) \varpi_{\mathbf{q}}$. According to the right angle $\triangle \mathbf{O G W}$ get the $\mathbf{O W}$ speed along point $\mathrm{W}$ is:

$$
\mathbf{v}_{\text {ow }}=\frac{\mathbf{R}_{0} \varpi_{\mathbf{q}} \sin \varpi_{\mathbf{b}}\left(\mathbf{t}+\mathbf{t}_{0}\right)}{\cos ^{2} \varpi_{\mathbf{q}}\left(\mathbf{t}+\mathbf{t}_{0}\right)}
$$

The relation of cutting edge along itself slipping is:

$$
\mathbf{G W}=\mathbf{R}_{0} \tan \varpi_{\mathbf{q}}\left(\mathbf{t}+\mathbf{t}_{0}\right)
$$

At the same time speed of cutting edge along itself direction slipping is GW:

$$
\mathbf{v}_{\mathrm{GW}}=\frac{\mathbf{R}_{0} \cdot \omega_{\mathbf{q}}}{\cos ^{2} \varpi_{\mathbf{q}}\left(\mathbf{t}+\mathbf{t}_{0}\right)}
$$

(4)

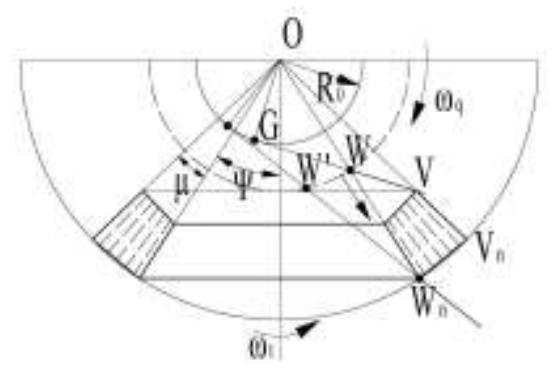

Figure 3.

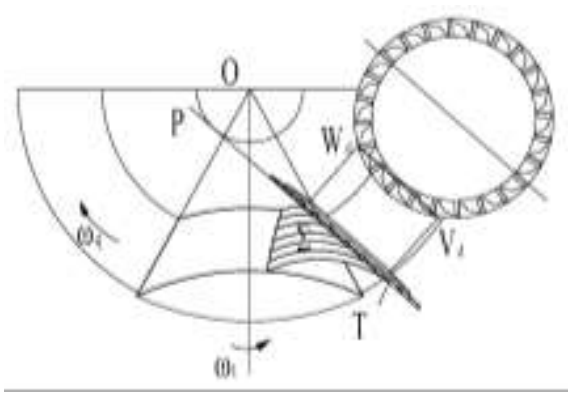

Figure 4.

Fig. 3. No over cutting skew bevel gear tooth surface generation

Fig.4. Machining process of skew bevel gear tooth surface with disc milling cutter

As shown in Fig.4, according to the characteristics of spiral bevel gear tooth surface is generated, disk shaped milling cutter is selected as the cutting tool to realize the tooth surface precision machining, the main cutting edge of the cutter teeth in the same plane, so the milling cutter edge of the main cutting and Q plane are perpendicular and intersected at the tooth generating line, therefore the main cutting edge is coincide with the the tooth surface that through generating line. The disc shaped cutter rotating with high-speed when the cutting tooth is machining, a rotary plane is formed by the main cutting edge, the string $\mathbf{W}_{\mathbf{d}} \mathbf{V}_{\mathbf{d}}$ in the rotary plane can be used as the tooth generating line to achieve the tooth surface generation motive. 


\section{The Analysis of Tooth Surface Machining Process}

In this paper, triaxial linkage bevel gear milling NC machine was developed according to the above cutting method. The bevel gear tooth surface machining and be realized by cutting tooth axis A, axis $\mathrm{C}$, axis $\mathrm{Y}$ linkage in the machining process, through rotating shaft $\mathrm{A}$ to implement workpiece rotating, through axis $\mathrm{Y}$ along the root cone linear to motive by linear, the revolution of axis $\mathrm{C}$ gear, the relative position of the tool and the workpiece is controlled, , cutting of bevel gear is realized.

At the end of the generating shape line $\mathrm{W}$ that coordinate is ywr in machining process, generating shape line along the root cone to move forward feed, that is the machine tool along the $Y$ axial forward feed; direction angle of the gear is $\gamma \mathrm{r}$, common corner machine tool of gear along the A axis to rotate; the workpiece self-rotation angle is $\phi r$, tooth surface machining motion equation is:

$$
\begin{aligned}
\mathbf{y}_{\mathrm{wrl}} & =-\mathbf{R}_{0} \tan \left(\varpi_{\mathrm{q}} \mathbf{t}_{\mathrm{r} 10}+\varpi_{\mathrm{q}} \mathbf{t}\right) \\
\gamma_{\mathrm{rl}} & =\pi-\varpi_{\mathrm{q}} \mathbf{t}_{\mathrm{rl} 0}+\psi_{\mathrm{fr}}-\varpi_{\mathrm{q}} \mathbf{t} \\
\phi_{\mathrm{rl} 1} & =\frac{\varpi_{\mathrm{q}} \mathbf{t}}{\sin \delta_{\mathrm{br}}}
\end{aligned}
$$

The initial position of the tool is:

$$
\varpi_{\mathbf{q}} \mathbf{t}_{\mathrm{rl} 0}=\cos ^{-1}\left(\frac{\mathbf{R}_{0}}{\mathbf{r}_{\mathrm{br}}} \cos \left(\mu_{\mathrm{fr}}+\psi_{\mathrm{fr}}\right)\right)-\mu_{\mathrm{fr}}
$$

And rbr as gear small end generatrix length of base cone long.

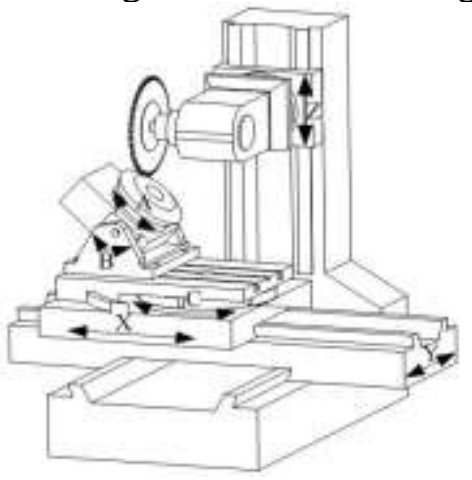

Figure 5. Bevel gear machining principle machine tools

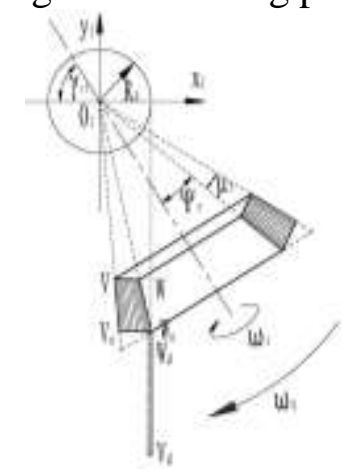

Figure 6. Tooth surface along the root of the small end over cutting

The tool setting work need to be completed before the machining of right tooth face , the initial position of the tool relative to the workpiece need to be found, coordinate $\mathrm{W}$ at the end of generating shape line is:

$$
\mathbf{y}_{\mathrm{wr} 00}=-\mathbf{R}_{0} \tan \left(\varpi_{\mathrm{q}} \mathbf{t}_{\mathrm{r} \mathbf{} 0}\right)
$$

The initial position of the horizontal rotary table is:

$$
\gamma_{\mathbf{r} 10}=\pi+\psi_{\text {fr }}-\varpi_{\mathbf{q}} \mathbf{t}_{\mathbf{r} 10}, \quad \phi_{\mathbf{r l} 0}=0
$$


Rotating angle for revolution that the tooth cutting from the small end of single tooth to big end of single tooth:

$$
\begin{aligned}
& \varpi_{q} \Delta t=\cos ^{-1}\left(\frac{R_{0}}{R_{b r}} \cos \psi_{r}\right)- \\
& \cos ^{-1}\left(\frac{R_{0}}{r_{b r}} \cos \left(\psi_{r}+\mu_{r}\right)\right)+\mu_{r}
\end{aligned}
$$

The angle of revolve on its axis is:

$$
\Delta \phi_{\mathrm{rl}}=\frac{\varpi_{\mathbf{q}} \Delta \mathbf{t}}{\sin \delta_{\mathrm{br}}}
$$

\section{The Milling Test and Inspection}

According to the mathematical model of skew bevel gear tooth surface, a accurate three-dimensional point cloud model of bevel gear is established under the matlab environment, at the same time in the theory of tooth surface measurement path is, after coordinate system that consistent with measuring coordinate system is established, the theoretical of coordinate grid nodes can be obtained. Then three coordinate measuring machine be used for measuring the actual grid node on the tooth surface. Mesh nodes data on the actual tooth surface is collected, that is space position error between the actual tooth surface and the theoretical tooth surface value on the tooth surface discrete points. The data points is introduced into Matlab that collected by three coordinate measuring machine through coordinate transformation, the tooth surface error of spiral bevel gear is used to evaluate.

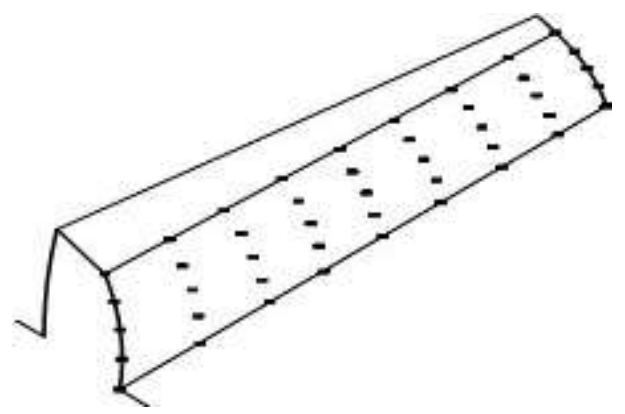

Figure 7. Tooth surface inspection point

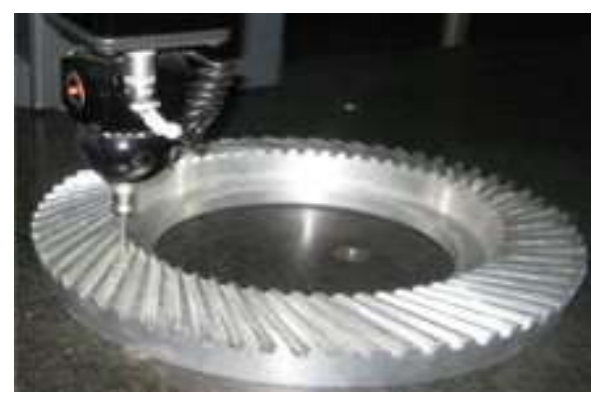

Figure 8. Three coordinate inspection of tooth face

After the measurement coordinate system is established, the probe of three coordinate measuring machine is preset to the normal vector direction of initial measurement point, along the measuring point vector direction to measure it. The two side surface of the spiral bevel gear tooth surface along the normal direction is respectively measured by the measuring machine in accordance with the 45 
tooth surface measuring nodes, as shown in Fig. 8. All teeth are successively measured, the final data is the average of all teeth.

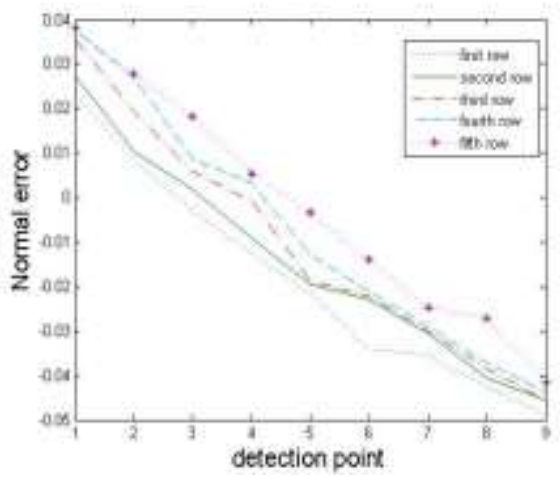

Figure 9. Error analysis of left tooth face

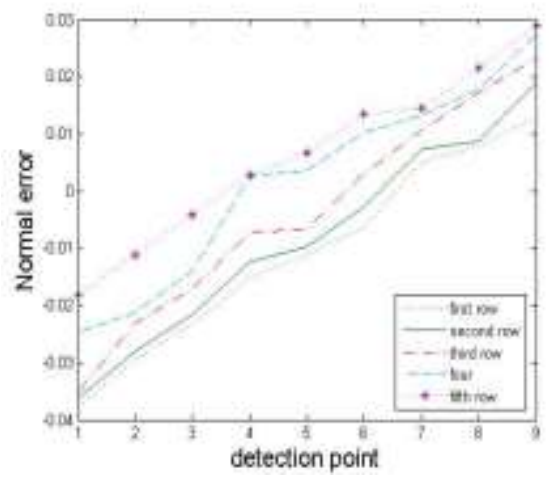

Figure .10 Error analysis of righttooth face

Measurement results show that on the left of gear tooth face the most-positive deviation is 0.0379 , max negative deviation is $0.0491 \mathrm{~mm}$; the right side of tooth face max deviation is $0.0289 \mathrm{~mm}$, max negative deviation is $0.0390 \mathrm{~mm}$. Deviation trend: the left side is the downward trend from small end to big end, the max deviation at the top of the small end tooth; the right side is the upward trend from small end to big end, the max deviation at the top of the small end tooth.

\section{Conclusions}

With the generating line of tooth surfac as the a string on the disc cutter during generating process of skew bevel gear, inverse motion of tooth surface generating motion that is used as the main motion of cutting tooth processing, without error of spherical involute skew bevel gear tooth surface can be obtained by milling of three-axis linkage, the motion process of gear cutting processing is greatly simplified. Improve the machining precision and machining efficiency of helical bevel gear, the cost of machine tool and the gear machining significantly is reduced. The formation of gear tooth surface which has the characteristics of the ideal spherical involute, so without matching processing, the exchange of cutting gear can be realized, and which the active control of tooth surface contact area can be realized, and the complicated adjustment process of traditional methods is avoided.

\section{Reference}

[1] Zhang Xuecheng, Hu Yong, Yang Zhaojun. Cutting movement analysis of spiral bevel gear based on tooth surface generating line [J].Journal of Beijing University of Technology, 2010,36(11): 1441-1446. 
[2]Gonzalez-Perez, Ignacio, Fuentes, Alfonso, Hayasaka, Kenichi, Analytical determination of basic machine-tool settings for generation of spiral bevel gears from blank data[J], ASME J. Mech. Des., 132, 2010, pp. 1-11.

[3] Beijing gear factory. Spiral Bevel Gear [M].Beijing; Science Press, 1974: 1-15.

[4]Faydor L. Litvin, Alfonso Fuentes, Kenichi Hayasaka, Design, manufacture, stress analysis, and experimental tests of low-noise high endurance spiral bevel gears[J], Mechanism and Machine Theory ,No. 41, 2006, pp.83-118.

[5]Jiang Wenbing. Research on five axis NC machining of spiral bevel gear [D].Zheng Zhou: Zheng Zhou University, 2003.

[6]Fan Qi, Ronald S. DaFoe, John W. Swanger, Higher-Order Tooth Flank Form Error Correction for Face-Milled Spiral Bevel and Hypoid Gears[J], ASME J. Mech. Des., no. 130, 2008, p. 072601.

[7]Zeng Tao. Design And Manufacture of Spiral Bevel Gear [M].Harbin: Harbin Institute of Technology Press, 1989.

[8]Vilmos Simon, Generation of Hypoid Gears on CNC Hypoid Generator[J], journal of mechanical design, Vol.133, No.12, 2011, pp.1-9.

[9]Yi-Pei Shih, A novel ease-off flank modification methodology for spiral bevel and hypoid gears[J], Mechanism and Machine Theory, 45, 2010, pp.1108-1124.219-226. 